Article

\title{
Predicting Nurses Burnout through Quality of Work Life and Psychological Empowerment: A Study Towards Sustainable Healthcare Services in Malaysia
}

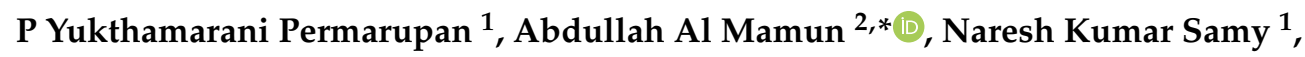 \\ Roselina Ahmad Saufi ${ }^{1}$ and Naeem Hayat ${ }^{1}$ (D) \\ 1 Faculty of Entrepreneurship and Business, Universiti Malaysia Kelantan, Kota Bharu 16100, Malaysia; \\ yuktha@umk.edu.my (P.Y.P.); naresh@umk.edu.my (N.K.S.); roselina@umk.edu.my (R.A.S.); \\ naeem.a18e013f@siswa.umk.edu.my (N.H.) \\ 2 Faculty of Business and Information Science, UCSI University, Cheras, Kuala Lumpur 56000, Malaysia \\ * Correspondence: mamun7793@gamil.com or 40466@ucsiuniversity.edu.my
}

Received: 20 November 2019; Accepted: 23 December 2019; Published: 3 January 2020

check for updates

\begin{abstract}
The nursing profession is a much-demanded profession that requires the individual capacity to work under intense physical and emotional dynamics in the workplace. Work related factors cause burnout and need attention from scholars and professionals to reduce the effects of the burnout among nursing staff. This study aimed to examine the meditational role of psychological empowerment and work-life quality on the burnout experiences of nursing staff in Malaysia. This study investigated a sample of 432 nursing staff from 10 registered hospitals in the Selangor area that have been listed on the Malaysian Health Tourism Council (MHTC) website. The responses collected via a self-reported questionnaire, and the data was analyzed using partial least square regression structural equation modelling (PLS-SEM). The findings statistically support the argument that the provision of quality of work-life (adequate and fair compensation, constitution in the work organization, safe and healthy working conditions, social integration in the work organization, social relevance of work-life, and work and life span) could promote psychological empowerment among nurses. Psychological empowerment statistically resulted in reducing the burnout effects by mediating the effect of work-life quality (QWL) on burnout. This study contributes to the literature that QWL factors need to be studied separately, and its affects on psychological empowerment, and how psychological empowerment permits curtails the effects of the burnout among nursing staff providing the services to health tourists. This study also provided important implications for the management staff of the nursing industry to initiate the management of burnout with the provision of psychological employment. The present study contributed to the current literature of burnout management through the psychological empowerment provided by the factors of the quality of work life.
\end{abstract}

Keywords: nurses; quality of work-life; psychological empowerment; burnout

\section{Introduction}

The highly demanding nature of work experienced by nursing professionals makes it one of the most stressful professions. The stressful nature of the nursing profession requires them to possess high physical and emotional resilience to tackle work-related issues so they can perform better at work [1]. The nurses are reported facing higher burnout effects in Malaysia [2]. The burnout reduces the amount of efforts by the nursing staff at the workplace, and they show emotional distance in their work. The cost of burnout is high for the nursing staff, the health industry, and the caretakers [3].

The performance of the nursing staff needs to be improved, and one of the options is to achieve higher work performance by empowering the nursing staff [4]. Employees can be empowered by 
providing them with the necessary working conditions otherwise defined as the work-life quality (QWL) [5]. Psychological empowerment can reduce stress and bring positive changes in the working environment of the nurses [6]. QWL is a combination of eight work characteristics in the workplace to achieve psychological empowerment. QWL factors are related to compensation, working environment, work hours, safety, and security at the workplace, development for future roles, and working with a cause for the society [5]. The non-availability of QWL factors was the major cause of poor performance and leaving among nursing professionals [4]. Enhancing the QWL enables the health service providers to recruit and keep qualified and inspired staff to provide health facilities to their customers [7]. Good health services delivery is associated with nursing staff that were provided better QWL to enhance psychological empowerment in reducing the effects of burnout [3].

Malaysia operated the two-tier health system, which are the public health care services provided by the Ministry of Health $(\mathrm{MOH})$ and the main resources generated by the tax system of the country [8]. The public sector health services used by 28 Million population of the nation. Another tier of the health system is run by the private sector and mainly used by the affluent class of the nation [9]. The private sector is more quality-based and associated with shorter service time. The private sector also supports the publicly provided health services in the country. The share of the private sector in the total health service of the country is about $26 \%$ [10]. However, the prices for the private sector health services are somewhat $10 \%$ higher.

The Malaysian health system is based on a two-tier system. The public sector is managed by the Ministry of Health $(\mathrm{MOH})$, with resources provided by the country's tax revenue, and its health services are enjoyed by the 28 Million Malaysians [8]. In contrast, the private sector provides health services to the affluent class with emphases on the quality and short service time. The private sector health services contribution to the country's health system is about $26 \%$, and has higher price tags as well. The Malaysian healthcare industry is growing to become a viable option for global healthcare travelers [9], although it is facing a shortage of healthcare professionals of about 25\% [11-13]. However, the objectives for the ETP in the healthcare sector are still far-reaching.

The shortage of nursing staff is caused by the stressful working conditions, job dissatisfaction, and burnout [12]. Moreover, nursing staff migration and nerve-wracking working conditions are reasons of attrition of nursing staff. The shortage of nursing staff in the Malaysian health system is caused by the burnout experience by the nursing staff in execution of their professional duties, associated with longer shifts, no social and emotional support systems, and highly stressful working conditions [14]. Therefore, this research aims to understand the effect of QWL on the psychological empowerment of Malaysian nursing staff and how psychological empowerment may affect burnout. The satisfaction of the nursing staff with their job and job structure can create competitive advantages for the Malaysian health industry to attract and serve more international customers [15]. The competitive advantages for the healthcare sector can only be achieved by the provision of QWL for the nursing staff [16]. The remedy for these conditions relies on the management of the healthcare sector institutions to determine the causes of burnout and provide the necessary working conditions to reduce the exposures of burnout by the nursing staff.

The next Section is about the literature regarding burnout, psychological empowerment, and QWL factors. The Section after the literature review describes the method of this study based on literature review and hypotheses development. The analysis and results are reported in Sections 4 and 5 , respectively. Section 6 presents the conclusions with future research opportunities and study limitations.

\section{Literature Review}

Nursing is a noble profession and plays an important role in patient care services and the health care of any country. Nurses work with patients and medical doctors as well as supporting the caretakers. The role of the nursing staff is undeniably important, and their duties are countless [7]. A good healthcare system relies on the nursing staff to facilitate health care services. However, the shortage of 
nursing staff and the poor working conditions become the major reasons for the nursing staff to be demotivated and to leave the profession [12].

\subsection{Burnout}

Positive perceptions of the work experience and work environment can cause a low level of stress which can positively influence the work engagement and professional commitment, whereas negative perceptions related to high strain can cause the state of depletion of resources namely burnout [17]. Burnout is the state of mind developed among service-oriented professionals [18]. It can reduce effectiveness, as well as declining the motivation and engagements in non-work related behaviors. Maslach [3] defined burnout as follows: "psychological syndrome that involves a prolonged response to chronic interpersonal stressors on the job." Burnout is a mental state developed over the period in a work environment with continuous stress related to work demands. If this mental-state is prolonged, it can cause physical and emotional distress [12]. Burnout has three dimensions, termed as the burnout inventory [18], namely: emotional exhaustion, depersonalization, and reduction in personal accomplishment. Moreover, recently, the international classification of diseases has categorised burnout as an occupational phenomenon, and not a medical condition, with three dimensions, namely: exhaustion, cynicism about the job, and loss of professional efficacy [19]. The emotional exhaustion is the prime factor of the burnout and associated with the overextension of work-related efforts physically and emotionally and leads to the depletion of perceived personal resources. In the end, the individual feels exhausted due to work. Depersonalization is the loss of feeling towards work-related issues and behaving in a non-human way [20]. It moves an individual self away from the work-related issues and so they perform without empathy in the work setting. The loss of interest in job-related matters and responding to work-related issues as non-issues are the depersonalization of the burnout dimension [16]. When an individual experiences emotional exhaustion and depersonalization, they will lose the desire for achievement and competence to perform. The individual loses the purpose and is not inclined to become successful in his or her job [20]. Burnout is the outcome of extended occupational stress that influences the individuals' service provider and service receiver in the health industry [18]. Studies reported that physicians and nurses who are affected by burnout tend to be involved in substance misuse [21], depression [22], or high rates of personal stress [23].

Moreover, patients are also at risk while getting treatments from burnout health care professionals. The cost of burnout is endured by the patients, patient's family, and hospitals [15]. It reported that nurses have a high level of work-related stress of about $49.3 \%$ in Malaysia [9]. Burnout includes emotional exhaustion, depersonalization, and low personal accomplishment [18].

\subsubsection{Emotional Exhaustion}

Emotional exhaustion is the feeling that one lacks physical and emotional personal resources. The depletion of resources can generate fatigue and loss of work motivation [24]. The individual might lack the energy to work and not have any interest, which can lead to resignation [3]. The individual might avoid customers and detach from work-related activities. Perceived stress was found to be one of the strongest predictors of emotional exhaustion [24].

\subsubsection{Depersonalization}

Depersonalization is the attitude of distancing oneself from work. People might lose their purpose in work and want to take a rest from work [24]. The uncaring and cold-hearted behavior towards customers is becoming the norm. Individuals start perceiving the clients as objects and not as people with needs and emotions [25]. The attachment to clients and caretakers become zero that leads to frustration and incompetence. 


\subsubsection{Low Personal Accomplishment}

Distance from personal accomplishment is the tendency to feel negatively on the accomplishment of work and to stop putting efforts to accomplish job assignments. The nursing staff felt unhappy and dissatisfied about their accomplishment at the workplace. The perception of unhappiness can influence them to not participating in work with full efforts and lead to a personal sense of failure [11]. The personal sense of failure becomes guilt, and the outcome is understood as the detachment from work and people at the workplace [24].

\subsection{Psychological Empowerment}

Individuals cognitively perceived empowerment is originated from the interactions with other colleagues and causes the development of individual motivation to behave competently with goal orientations [26]. It is a cognitive state of mind related to the development of perception at the workplace and provides the necessary energy for the individuals to perform with full capacity for the welfare of the organization with four empowerment bases [27]. Psychological empowerment is a process that starts with the cognition that good things happen around the individual and subjectively transforms the perception of workers to get involved in the accomplishment of the work-related tasks with full efforts [28]. The development of psychological empowerment is based on four processes, namely: meaning, competence, self-determination, and impact.

\subsubsection{Meaning}

The sense of purpose developed through the meaning domain. The work and individual beliefs and values are similar to each other. The sense of purpose categorizes the two divergent beliefs into one [29]. Meaning enables an individual to develop a psychological relationship with the organization.

\subsubsection{Competence}

Competence is associated with the notion of self-efficacy belief on the capacity to perform with the skills set of the individuals [29]. Competence helps individuals to utilize their full potential to fulfil organizational welfare and develop the belief that work assignments are their responsibility. It can lead to exerting full strength for the work [5].

\subsubsection{Self-Determination}

Self-determination is associated with autonomy and freedom to make choices at the workplace. Self-determination helps in building confidence and a necessary personal sense of freedom to take charge of the work and workplace [5]. Individuals at workplace perceive having the autonomy to start or manipulate the work routines as good for the organization [29].

\subsubsection{Impact}

The impact is the perceived outcome of an individual's control at the workplace. The perception of the degree of control can influence individuals to make something good for the organization, as they put more efforts and treat the work as their own [27]. Psychological empowerment is a technique to empower employees to work well for the organization and themselves [5].

\subsection{Quality of Work Life}

Work activity is important in the development of the physical and mental dimensions of individuals. Work-life is associated with a work environment where people come together to accomplish similar objectives [12]. Work activities are considered un-purposeful and become a burden if the work activities based on the notion of no involvement, are unsatisfactory and non-rewarding [5]. Work-life is based on the concept of involvement and reward for both parties, such as employers and employees. However, Walton [30] describes the quality of work-life as an organizational ability to meet the individual 
employee essential needs with eight dimensions. Work-life quality is based on the processes that an organization develops for the achievement of work performance that benefits the workforce and society.

\subsubsection{Adequate and Fair Compensation}

A fundamental reason for any person's employment is the salary or wage for his or her time and efforts. The perception of adequate and fair compensation is attached to equal pay for equal work, and the payment is incompatible with other peer workers [5]. The satisfaction with compensation such as adequacy and fairness have positive effects on the perception of work.

\subsubsection{Safe and Healthy Environment}

A worker is always looking for a safe workplace and the work environment in terms of physical and psychological nature [7]. Safety fulfils the human needs for security, and time satisfies the psychological needs that a person has himself or herself and her family after working hours. The nature of work and working environment should be safe, and the provision of protective equipment as working instruments is required to create a safe and healthy working condition [5].

\subsubsection{Development of Human Capacities}

It is human nature to develop and advance in their career. The development of human capacities is necessary as a motivation factor [23], such as: skills enhancement, provision of learning opportunities, work-related training, and developmental plans contributing to the quality of work-life among nurses [11].

\subsubsection{Social Integration in the Work Environment}

Humans are social beings who want to socially integrate into society and the workplace. The social attachment at the workplace develops necessary belongings to the workplace and the peers [14]. Spending more time with colleagues and patients shows a negative relationship with the occurrence of burnout [31]. Organizations are intended to have social integration to achieve necessary team orientation at the workplace so that their employees can work better in a cohesive work environment [23].

\subsubsection{Constitutionalism}

Organizations have a structure, which provides the position holder with the necessary powers to relate to the executives at the workplace [23]. The provision of expression at the workplace without fear and not dominated by higher ranks but only with constitutionalism.

\subsubsection{Total Life Space}

It is a balance of time that a person spends at the workplace and his/her personal life. Human beings require leisure and family time to balance their lifestyle [7]. The rest time at the workplace and workday within specific times have a positive effect on individual work performance [23].

\subsubsection{Social Relevance}

Organizations are social platforms and employees are the agents of their respective organizations. The work of an organization is for social purposes [5]. However, a few organizations are regarded as more socially relevant, and some are less socially relevant [10]. Social relevance is the degree to which the workers view that the organization is socially responsible, and they regard their contribution to the organization as a social value [7]. 


\subsection{Hypotheses Development}

\subsubsection{Adequate and Fair Compensation and Psychological Empowerment}

Adequate compensation always has a positive effect on employee work and the psychological condition of the workers [7]. The feeling of satisfaction with the salary, that it is enough and fair when compared with other peers, has a positive effect on the personal wellbeing and the perception that 'I am getting fair pay for my work' can lead to psychological empowerment [5]. Therefore, the following hypothesis presented:

Hypothesis 1a (H1a): Adequate and fair compensation has a positive effect on psychological empowerment.

\subsubsection{Constitution in Work Organization and Psychological Empowerment}

A workplace that has a structure and provides the opportunity to express feelings regarded as a good workplace. At the workplace, people work together and have the delegated powers to perform organizational jobs [7]. Power structure enables the working of the organization without eliminating individual rights. The constitution at the workplace is important in creating a sense of power for all the employees. The satisfaction of the employees with the constitution at the workplace can lead to psychological empowerment which leads to the following hypothesis:

Hypothesis 1b (H1b): Constitution in the work organization has a positive effect on psychological empowerment.

\subsubsection{Opportunity for Growth, Security, and Psychological Empowerment}

It is natural for human beings to ask for security and growth. Employees need to grow in the workplace and have a sense of security [23]. The growth can result in career opportunity provided by the organization [7]. The growth opportunity inside the organization can provide through a training session and study leaves [23]. The growth opportunity can provide psychological empowerment to the employees [5]. Moreover, job security is also important for more psychological empowerment. Hence, this study presents the following hypothesis:

Hypothesis 1c (H1c): Opportunity for growth and security has a positive effect on psychological empowerment.

\subsubsection{Opportunity to Use and Develop Human Capital and Psychological Empowerment}

A human would look for opportunities to improve their profession and skills in managing multiple tasks. They like to be evaluated respectably and provided with the opportunities to develop skills for new job roles with different responsibilities [5]. Acquiring new skills enables job enlargement and enhances psychological empowerment [17]. The discussion leads to the following hypothesis:

Hypothesis 1d (H1d): The perception of an opportunity to use and develop human capital has a positive effect on psychological empowerment.

\subsubsection{Safe and Healthy working conditions and Psychological Empowerment}

A safe and healthy workplace is important as the workers need a physically safe and healthy working environment. The work environment enables smooth and efficient safe work at the workplace [6]. Moreover, the working equipment needs to be available and safe. The work shifts and managed workload create the perception of meaning and control for the workers. The availability of necessary equipment fosters the influence of the workplace [14]. Therefore, this following hypothesis presented:

Hypothesis 1e (H1e): Safe and healthy working conditions have a positive effect on psychological empowerment. 


\subsubsection{Social Integration and Psychological Empowerment}

The safe and healthy working environment is not enough to enrich the work experience at the workplace. Employees want their belief and race respected in the workplace [23]. The relationship at the workplace can energise the workplace into a likeable place to work. The working relationship and sense of respect can develop the meaning for the work and strengthen competency [6]. Employees start working in teams and have a mindset to help each other [14]. Therefore, the following hypothesis presented:

Hypothesis 1f (H1f): Social integration in an organization has a positive effect on psychological empowerment.

\subsubsection{The Social Relevance of Work Life and Psychological Empowerment}

Values are important antecedents of human behaviors. Value matching is good for employees and employers, whereas social relevance is important to provide input on the cause of work routines [7]. Some of the important attributes of social relevance provided by an organization are organization image, feeling of pride, integration with society, and quality of product and services [14]. Social relevance can have a positive effect on the perception of psychological empowerment [11], besides having more meaning of work and image. Therefore, the following is the hypothesis:

Hypothesis 1g (H1g): Social relevance of work-life has a positive effect on psychological empowerment.

\subsubsection{Work and Total Life Span and Psychological Empowerment}

Workers need the rest and spend time with their families. Work routines that provide a break and rest time, as well as a holiday, will positively affect the perception of workers on their work [7]. Rest and break times provide control over the job and enhance the perception of autonomy at the workplace [11]. Therefore, the following hypothesis presented:

Hypothesis 1h (H1h): Work and total life span have a positive effect on psychological empowerment.

\subsubsection{Psychological Empowerment and Burnout}

Employees can develop psychological empowerment with perceived importance, confidence, autonomy, and meaningful work [6]. Enhanced empowerment can curtail the state of exhaustion and energize the worker that the work and workplace are important [24]. Therefore, the following hypothesis presented:

Hypothesis 2 (H2): Psychological empowerment has a negative effect on burnout.

\subsubsection{The Meditational Role of Psychological Empowerment}

The effect of adequate and fair compensation, the constitution in an organization, the opportunity for growth and security, opportunity to use and develop human capital, safe and healthy working conditions, social integration in an organization, the social relevance of work-life, and work and total life span on psychological empowerment was established by earlier studies [12]. Burnout is tackle by the role of psychological empowerment [4]. The meaning of work, self-determination, and impact can reduce burnout [5]. This discussion addresses the issue of the burnout by adding features of QWL at the workplace in building psychological empowerment [4]. Therefore, the following is the hypothesis of this study:

Hypothesis 3 (H3): Psychological empowerment mediates the relationship between adequate and fair compensation, constitution in an organization, opportunity for growth and security, opportunity to use and develop human capital, safe and healthy working conditions, social integration in an organization, social relevance of work-life, and work and total life span on burnout. 


\section{Research Methodology}

\subsection{Sample Selection and Data Collection}

The sample size for this study was calculated using GPower V2.0 software for the multiple regression statistical analysis with the following setting: statistical significance at 0.05 with the statistical power fixed at 0.95 for null hypothesis rejection level and a medium level of effect size at 0.15. The sample size is 129 and rounds off to 130. This study used the table of Krejcie and Morgan [32] and determined that 378 respondents was a sufficient sample size for the study. The population of this study consisted of full-time registered nurses employed in 78 hospitals registered under $\mathrm{MOH}$. This study collected data from ten registered hospitals (selected the ten hospitals most visited tourist patients in 2017) in Selangor and Kuala Lumpur, Malaysia, which have been listed on the MHTC website, amounting to a total of 1620 registered nurses. A total of 550 questionnaires equally distributed to the selected hospitals after obtaining permission from the Chief Matron of each hospital. The Chief Matron of each hospital selected the potential respondent and distributed the survey instrument. The survey run from September 2018 to October 2018 and 467 completed questionnaires were received. Consent from the study respondents obtained in the form of their signature on the questionnaire form. The source of funding for research disclosed and that the respondents informed that their information would not disclose for any other purposes than for this research. However, after screening for incomplete and suspicious response patterns, another 35 responses were dropped, so the final number of questionnaires used for the analysis was 432 .

\subsection{Research Instrument}

This study used an established questionnaire to collect the data. The concept for the quality of work-life has eight sub-dimensions: (1) adequate and fair compensation; (2) safe and healthy environment; (3) development of human capacities; (4) growth and security; (5) social integration in work environment; (6) constitutionalism; (7) total work-life space; and (8) social relevance. A total of 35 items were adopted from the scale by Walton [30]. Psychological empowerment with four sub-domains was adopted from Spreitzer [29], namely: meaning, impact, self-determination, and competence. Each domain has three items in which there are 12 items to estimate psychological empowerment. The estimation of burnout was performed using Maslach's burnout inventory (MBI) which has 13 items with three sub-domains, namely emotional exhaustion, depersonalization, and personal accomplishment [20]. The reported reliability coefficient for the scale was $\alpha=0.91$ for emotional exhaustion, $\alpha=0.85$ for depersonalization, and $\alpha=0.87$ for personal accomplishment. Furthermore, this study adopted the seven-point Likert scale (1 to 5, from 'strongly disagree' to 'strongly agree') for all variables.

\subsection{Common Method Variance (CMV)}

The treatment of CMV made during the pre-data-collection stage, data collection stage, and analysis stage. As this study adopted the instruments prom earlier studies, this study; therefore, Harman's single-factor analysis was used to estimate the CMV [33]. It suggested that the single factor must be extracted less than $40 \%$ variance to establish the controlled level of CMV within the constructs [34]. The Harman single-factors of this study was $26.01 \%$ in which CMV was not a serious issue.

\subsection{Multivariate Normality}

The multivariate normality was not a critical issue for SEM-PLS. This study checked the multivariate normality of the data to validate the use of SEM-PLS with the data set [35]. This study also used web power to test the multivariate normality of the data set. The web power online tool provided the results for skewness and kurtosis coefficients with a $p$-value for the data set. The data considered 
non-normal if the $p$-value for the Mardia's multivariate coefficient is more than 0.05 [36]. The result of this study was normal.

\subsection{Data Analysis Method}

PLS-SEM method has the capacity to deal to with complex model with many constructs, without assumption of data normality. PLS-SEM has a causal-predictive nature to enables the researcher to deal with model requires causal explanation and having complex by nature. The models in PLS-SEM are tested using two stages in which Cronbach's alpha $(\alpha)$ and composite reliability (CR) are used to report the intern consistency of the constructs. The recommended scores for $\alpha$ and CR are 0.70 or above [37]. However, $C R$ is considered a good indicator of internal reliability than $\alpha$. The average variance extracted (AVE) value must be 0.50 or above for every construct [38]. The variance inflation factor (VIF) represents the inflation of variance due to the presence of multicollinearity within the constructs [36]. The discriminant validity in PLS-SEM is verified using Fornell-Larcker, and heterotrait-monotrait ratio (HTMT). The Fornell-Larcker criterion needs to be above 0.700 to provide evidence of discriminate validity. However, a new test of HTMT suggested for the discriminate validity, and the values must be less than 0.90 . The measurement model represented with $r^{2}$ that denotes the explanation power of endogenous variables with exogenous variables. The effect size $\left(f^{2}\right)$ and $Q^{2}$ are the estimates of the measurement model. The effect size $\left(f^{2}\right)$ signifies the effect of each exogenous variable on the endogenous variable. Cohen [39] offered the guidelines to means the $\left(f^{2}\right)$. The effect sizes of $0.30,0.15$, and 0.02 represent large, medium, and small effects respectively. The $Q^{2}$ values of $0.02,0.15$, and 0.35 indicate small, medium, and large predictive relevancy of the model respectively [38].

\section{Data Analysis}

\subsection{Descriptive Statistics}

Table 1 presents the profile of the respondents. The majority of the respondents, with a total of $85 \%$ were female. The majority of the respondents, with a total of $86 \%$ were 31 years old and above. However, $32.2 \%$ of the respondents were single, and the rest were married or divorced and widowed. A total of $78.9 \%$ of the respondents have a college degree in nursing in which $2.1 \%$ of them have a master degree. The minimum qualification of the respondents was a certificate. About $58 \%$ of the respondents have working experiences of six years or above. The respondents with working experiences of two years or less were about $42 \%$.

Table 1. Profile of the Respondents.

\begin{tabular}{ccc}
\hline & $\mathbf{n}$ & $\mathbf{\%}$ \\
\hline Gender & & \\
Male & 65 & 15 \\
Female & 377 & 85 \\
Total & 432 & 100 \\
\hline Education & & \\
Certificate & 82 & 19 \\
Degree & 341 & 78.9 \\
Master & 9 & 2.1 \\
Total & 432 & 100 \\
\hline Working Experience & & \\
less than 2Years & 11 & 2.5 \\
2-5 Years & 174 & 40.3 \\
6-10 Years & 154 & 35.6 \\
10-15 Years & 47 & 10.9 \\
16-20 Years & 46 & 10.6 \\
Total & 432 & 100 \\
\hline
\end{tabular}


Table 1. Cont.

\begin{tabular}{ccc}
\hline & $\mathbf{n}$ & $\mathbf{\%}$ \\
\hline Age & & \\
Less than 30 years of age & 57 & 13.2 \\
31-41 years of age & 228 & 52.8 \\
42-52 years of age & 95 & 22 \\
53 and above of age & 52 & 12 \\
Total & 432 & 100 \\
\hline Marital Status & & \\
Single & 139 & 32.2 \\
Married & 249 & 57.6 \\
Divorced & 42 & 9.7 \\
Widowed & 2 & 0.5 \\
Total & 432 & 100 \\
\hline Nationality & & \\
Malaysian & 315 & 72.9 \\
Non-Malaysian & 117 & 28.1 \\
Total & 432 & 100 \\
\hline
\end{tabular}

\subsection{Validity and Reliability}

This study followed the authorisation by the Hair et al. [38] in which the Cronbach's alpha $(\alpha)$ and composite reliability (CR) must be 0.70 or greater for each construct. Table 2 shows that the $\alpha$ and CR values for each construct are more than 0.841 and 0.894 , respectively. The Cronbach's alpha is the measure of inter-correlational approximation for the items for each construct. The Cronbach's alpha value is 0.841 , which is the minimum value and the other constructs have Cronbach's values above the prescribed limit of 0.70 . The Cronbach's alpha and CR values signify that the constructs were reliable before performing the next analysis. The AVE of all items for each construct must be above 0.50 to achieve convergent validity in approving the uni-dimensionality of each construct [38]. The items show that the constructs have acceptable convergent validity. The results show that the item loads on their particular variables fulfil the postulation of discriminant validity shown in Table 2. Another test for discriminant validity is Fornell-Larcker criterion. The results show that the values are in an acceptable range. Another recommended examination for discriminant validity is HTMT ratio. The HTMT values must be 0.90 or fewer to confirm discriminant validity [37]. Table in Appendix A show that the results of discriminant validity.

Table 2. Reliability analysis.

\begin{tabular}{|c|c|c|c|c|c|}
\hline Variables & $\begin{array}{c}\text { Item } \\
\text { Loading }\end{array}$ & $\begin{array}{l}\text { Cronbach's } \\
\text { Alpha }\end{array}$ & $\begin{array}{l}\text { Composite } \\
\text { Reliability }\end{array}$ & $\begin{array}{l}\text { Average Variance } \\
\text { Extracted }\end{array}$ & $\begin{array}{c}\text { Variance } \\
\text { Inflation Factor }\end{array}$ \\
\hline $\begin{array}{l}\text { Adequate and fair } \\
\text { compensation } \\
\text { (4 Items) }\end{array}$ & $\begin{array}{l}0.929 \\
0.946 \\
0.953 \\
0.928 \\
\end{array}$ & 0.955 & 0.968 & 0.882 & 2.723 \\
\hline $\begin{array}{l}\text { Constitution in the } \\
\text { work organization } \\
\text { (4 Items) }\end{array}$ & $\begin{array}{l}0.946 \\
0.957 \\
0.945 \\
0.938 \\
\end{array}$ & 0.961 & 0.972 & 0.896 & 3.134 \\
\hline $\begin{array}{l}\text { Opportunity to } \\
\text { growth and } \\
\text { security } \\
\text { (4 Items) }\end{array}$ & $\begin{array}{l}0.906 \\
0.900 \\
0.849 \\
0.817\end{array}$ & 0.859 & 0.905 & 0.707 & 3.366 \\
\hline
\end{tabular}


Table 2. Cont.

\begin{tabular}{|c|c|c|c|c|c|}
\hline Variables & $\begin{array}{c}\text { Item } \\
\text { Loading }\end{array}$ & $\begin{array}{l}\text { Cronbach's } \\
\text { Alpha }\end{array}$ & $\begin{array}{l}\text { Composite } \\
\text { Reliability }\end{array}$ & $\begin{array}{l}\text { Average Variance } \\
\text { Extracted }\end{array}$ & $\begin{array}{c}\text { Variance } \\
\text { Inflation Factor }\end{array}$ \\
\hline $\begin{array}{l}\text { Opportunity to use } \\
\text { and develop } \\
\text { human capital } \\
\text { (5 Items) }\end{array}$ & $\begin{array}{l}0.948 \\
0.858 \\
0.967 \\
0.939 \\
0.872\end{array}$ & 0.954 & 0.964 & 0.842 & 6.179 \\
\hline $\begin{array}{l}\text { Safe and healthy } \\
\text { working condition } \\
\text { (6 Items) }\end{array}$ & $\begin{array}{l}0.881 \\
0.785 \\
0.857 \\
0.851 \\
0.786 \\
0.843\end{array}$ & 0.841 & 0.891 & 0.600 & 3.192 \\
\hline $\begin{array}{l}\text { Social integration } \\
\text { in work } \\
\text { organization } \\
\text { (4 Items) }\end{array}$ & $\begin{array}{l}0.838 \\
0.880 \\
0.880 \\
0.898\end{array}$ & 0.884 & 0.920 & 0.743 & 2.540 \\
\hline $\begin{array}{l}\text { Social relevance of } \\
\text { work life } \\
\text { (5 Items) }\end{array}$ & $\begin{array}{l}0.837 \\
0.903 \\
0.898 \\
0.894 \\
0.811\end{array}$ & 0.906 & 0.930 & 0.729 & 2.259 \\
\hline $\begin{array}{l}\text { Work and life span } \\
\quad \text { (3 Items) }\end{array}$ & $\begin{array}{l}0.735 \\
0.790 \\
0.718\end{array}$ & 0.854 & 0.912 & 0.775 & 2.093 \\
\hline $\begin{array}{l}\text { Psychological } \\
\text { empowerment } \\
\text { (12 Items) }\end{array}$ & $\begin{array}{l}0.834 \\
0.769 \\
0.893 \\
0.751 \\
0.894 \\
0.923 \\
0.826 \\
0.943 \\
0.785 \\
0.956 \\
0.834 \\
0.893\end{array}$ & 0.963 & 0.967 & 0.712 & - \\
\hline $\begin{array}{l}\text { Burnout } \\
\text { (13 Items) }\end{array}$ & $\begin{array}{l}0.843 \\
0.823 \\
0.829 \\
0.788 \\
0.734 \\
0.780 \\
0.876 \\
0.865 \\
0.863 \\
0.705 \\
0.845 \\
0.751 \\
0.892\end{array}$ & 0.931 & 0.941 & 0.563 & - \\
\hline
\end{tabular}

\subsection{Hierarchical Models}

This study includes a higher-order construct, psychological empowerment and burnout, which is affected by its respective first-order constructs. For this study, the first-order constructs, namely meaning, impact, self-determination, and competence have a positive and significant effect on the second-order construct of psychological empowerment. Moreover, the first-order constructs, namely emotional exhaustion, personal accomplishment, and depersonalization had a positive and significant effect on the second-order construct. Table 3 presents the result that the first-order construct namely meaning $(\beta=0.275, p=0.000)$, impact $(\beta=0.235, p=0.00)$, self-determination $(\beta=0.254, p=0.000)$, and 
competence $(\beta=0.278, p=0.000)$ have a positive and significant effect on psychological empowerment. The first order of construct namely emotional exhaustion $(\beta=0.640, p=0.000)$, personal accomplishment $(\beta=0.199, p=0.000)$, and depersonalization $(\beta=0.304, p=0.000)$ has a positive and significant effect on burnout from the second-order construct.

Table 3. Hierarchical models.

\begin{tabular}{ccccc}
\hline & Coefficient & T-Values & Sig. & Decision \\
\hline & Sub-Dimensions of Psychological & Empowerment & \\
\hline MEN $\rightarrow$ PYE & 0.275 & 70.197 & 0.000 & Supported \\
IMT $\rightarrow$ PYE & 0.235 & 88.016 & 0.000 & Supported \\
SED $\rightarrow$ PYE & 0.254 & 88.968 & 0.000 & Supported \\
COM $\rightarrow$ PYE & 0.278 & 66.987 & 0.000 & Supported \\
\hline \multicolumn{5}{c}{ Sub-Dimensions of Burnout } \\
\hline EEX $\rightarrow$ BUT & 0.640 & 51.858 & 0.000 & Supported \\
PAC $\rightarrow$ BUT & 0.199 & 12.238 & 0.000 & Supported \\
DPN $\rightarrow$ BUT & 0.304 & 32.462 & 0.000 & Supported \\
\hline
\end{tabular}

Note: MEN: meaning; IMT: impact; SED: self-determination; COM: competence; EEX: emotional exhaustion; PAC: personal accomplishment; DPN: depersonalization; PYE: psychological empowerment; BUT: burnout.

\subsection{Path Analysis}

After the exploration of model validity, reliability tests, and effects of the first order of the constructs on the second-order construct, namely psychological empowerment and burnout with the repeated indicator approach. The next step is the analysis on the effects of adequate and fair compensation, constitution in an organization, opportunity for growth and security, opportunity to use and develop human capital, safe and healthy working condition, social integration in an organization, social relevance of work-life, and work and life span on psychological empowerment and burnout. The adjusted $r^{2}$ value for the eight input variables (i.e., adequate and fair compensation; constitution in an organization; opportunity for growth and security; opportunity to use and develop human capital; safe and healthy working condition; social integration in an organization; social relevance of work-life; work and life span) on psychological empowerment made up 68.3 per cent of variance on psychological empowerment. The predictive relevance value $\left(\mathrm{Q}^{2}\right)$ for the part of the model is 0.448 , indicating a large predictive relevance. The adjusted $r^{2}$ value for psychological empowerment on burnout is 33.3 percent which reveals that $33.3 \%$ of the variance in the burnout can explain by psychological empowerment. The predictive relevance value $\left(\mathrm{Q}^{2}\right)$ for this part of the model is 0.158 , indicating a small predictive relevance.

Table 4 presents the standardized path coefficients, $t$-values, and significance level. The path coefficient for adequate and fair compensation on psychological empowerment provides the support to accept H1 ( $\beta=0.242, p=0.000)$. The result shows that the effect of adequate and fair compensation on psychological empowerment is positive and significant. The path coefficient for the constitution in an organization on psychological empowerment is positive and significant $(\beta=0.122, p=0.018)$. The result reveals that $\mathrm{H} 1 \mathrm{~b}$ is supported. The path coefficient for the opportunity for growth and security on psychological empowerment is $\beta=0.183$ and $p=0.002$. The result reveals that the effect of opportunity for growth and security on psychological empowerment is positive and significant. Hence, H1c is supported. The path coefficient for the opportunity to use and develop human capital on psychological empowerment is $\beta=-0.150$ and $p=0.051$, indicating a negative but significant effect. Hence, H1d is not supported. The path coefficient for safe and healthy working conditions on psychological empowerment is $\beta=-0.047$ and $p=0.256$, indicating a negative and insignificant effect. Hence, H1e is not supported. The path coefficient for the social integration in an organization on psychological empowerment is $\beta=0.309$ and $p=0.000$, depicting a positive and significant effect. Hence, H1f is supported. The path coefficient for the social relevance of work-life on psychological empowerment is $\beta=0.197$ and $p=0.000$, depicting a positive and significant effect. Hence, H1g is supported. The path 
coefficient for work life span on psychological empowerment is $\beta=0.129$ and $p=0.005$, a positive and significant effect. Hence, $\mathrm{H} 1 \mathrm{~h}$ is supported. The path coefficient for psychological empowerment on burnout is $\beta=-0.579$ and $p=0.000$ ), depicting a positive and significant effect. Hence, $\mathrm{H} 2$ is supported. Table 4 shows the results of path coefficients.

Table 4. Hypothesis Testing.

\begin{tabular}{cccccccc}
\hline \multicolumn{2}{c}{ Hypothesis } & Coefficient & t-Values & Sig. & $\boldsymbol{R}^{\mathbf{2}}$ & $\boldsymbol{F}^{\mathbf{2}}$ & Decision \\
\hline H1a & AFC $\rightarrow$ PYE & 0.242 & 3.720 & 0.000 & & 0.069 & Supported \\
H1b & CWO $\rightarrow$ PYE & 0.122 & 2.114 & 0.018 & & 0.001 & Supported \\
H1c & OGS $\rightarrow$ PYE & 0.183 & 2.856 & 0.002 & & 0.032 & Supported \\
H1d & ODH $\rightarrow$ PYE & -0.150 & 1.636 & 0.051 & & 0.012 & Not Supported \\
H1e & SHW $\rightarrow$ PYE & -0.047 & 0.657 & 0.256 & & 0.002 & Not Supported \\
H1f & SIW $\rightarrow$ PYE & 0.309 & 2.472 & 0.000 & & 0.121 & Supported \\
H1g & SRW $\rightarrow$ PYE & 0.197 & 6.114 & 0.000 & 0.683 & 0.056 & supported \\
H1h & WLS $\rightarrow$ PYE & 0.129 & 2.558 & 0.005 & & 0.026 & Supported \\
H2 & PYE $\rightarrow$ BUT & -0.579 & 20.615 & 0.000 & 0.333 & 0.503 & Supported \\
\hline
\end{tabular}

Note: AFC: adequate and fair compensation; CWO: constitution in the work organization; OGS: opportunity to growth and security; ODH: opportunity to use and develop human capital; SHW: safe and healthy working condition; SIW: social integration in work organization; SRW: social relevance of work-life; WLS: work and life span; PYE: psychological empowerment; BUT: burnout.

\subsection{Mediating Effects}

The mediating effect of psychological empowerment was tested on adequate and fair compensation, constitution at an organization, opportunity for growth and security, opportunity to use and develop the human capital, safe and healthy working condition, social integration at workplace, social relevance of work-life, and work and life span on the perceptions of burnout among the nurses. Table 5 shows the findings of the meditational effect of psychological empowerment. The results reveal that adequate and fair compensation is mediated by psychological empowerment for the burnout of organizational resilience $(\beta=-0.140, p=0.000)$. The outcome for the constitution for an organization is mediated by psychological empowerment for the burnout $(\beta=-0.071, p=0.018)$. The opportunity for growth and security is mediated by psychological empowerment for the burnout $(\beta=-0.106, p=0.003)$. The results show that the opportunity to use and develop human capital is mediated by psychological empowerment for the burnout $(\beta=0.087, p=0.054)$. The results reveal that safe and healthy working condition is not mediated by psychological empowerment for the burnout $(\beta=0.027, p=0.255)$. It revealed that social integration in an organization is mediated by psychological empowerment for the burnout $(\beta=-0.179, p=0.000)$. The social relevance of work-life is also mediated by psychological empowerment for the burnout $(\beta=-0.114, p=0.000)$. Lastly, work and life span mediated by psychological empowerment for the burnout $(\beta=-0.075, p=0.006)$.

Table 5. Meditating Effect.

\begin{tabular}{cccccc}
\hline & $\boldsymbol{\beta}$ & CI-min & CI-max & Sig. & Decision \\
\hline $\mathrm{AFC} \rightarrow$ PYE $\rightarrow$ BUT & -0.140 & -0.204 & -0.082 & 0.000 & Mediation \\
$\mathrm{CWO} \rightarrow$ PYE $\rightarrow$ BUT & -0.071 & -0.125 & -0.014 & 0.018 & Mediation \\
$\mathrm{OGS} \rightarrow$ PYE $\rightarrow$ BUT & -0.106 & -0.169 & -0.045 & 0.003 & Mediation \\
$\mathrm{ODH} \rightarrow$ PYE $\rightarrow$ BUT & 0.087 & 0.002 & 0.173 & 0.054 & Mediation \\
$\mathrm{SHW} \rightarrow$ PYE $\rightarrow$ BUT & 0.027 & -0.045 & 0.091 & 0.255 & No Mediation \\
$\mathrm{SIW} \rightarrow$ PYE $\rightarrow$ BUT & -0.179 & -0.236 & -0.130 & 0.000 & Mediation \\
$\mathrm{SRW} \rightarrow$ PYE $\rightarrow$ BUT & -0.114 & -0.158 & -0.063 & 0.000 & Mediation \\
WLS $\rightarrow$ PYE $\rightarrow$ BUT & -0.075 & -0.038 & -0.030 & 0.006 & Mediation \\
\hline
\end{tabular}

Note: AFC: adequate and fair compensation; CWO: constitution in the work organization; OGS: opportunity to growth and security; ODH: opportunity to use and develop human capital; SHW: safe and healthy working condition; SIW: social integration in work organization; SRW: social relevance of work-life; WLS: work and life span; PYE: psychological empowerment; BUT: burnout. 


\section{Discussion}

This study aimed to investigate psychological empowerment as a resource for healthcare providers (nurses) to reduce the likelihood of burnout among staff nurses, and the factors of QWL as predecessors of psychological empowerment. Nurses in Malaysia are at increased risk of burnout. Therefore, it is important for healthcare industry managers to understand and effectively manage burnout among staff nurses in Malaysia.

The study results revealed the effects of burnout in the nursing profession. Psychological empowerment is positively, statistically, and significantly affected by adequate and fair compensation, constitution at work, safe and healthy working conditions, social integration at work, social relevance of work-life, and work and life span as the factors of QWL. This result confirmed that the psychological empowerment of nurses in Malaysia is affected by the factors of QWL. Overall, H1, H2, H3, H6, H7, and $\mathrm{H} 8$ are accepted. The most important factor of QWL that influences psychological empowerment is social integration in an organization $\left(f^{2}=0.121\right)$ with a medium effect, followed by adequate and fair compensation $\left(f^{2}=0.069\right)$ with a small effect size, and the third most influencing factor is social relevance of work-life $\left(f^{2}=0.056\right)$ with a small effect size (see Table 4). Meng et al. [4] documented QWL factors as structural factors that positively affected psychological empowerment. However, the opportunity for growth and security and the opportunity to use and develop human capital has a negative effect on psychological empowerment. Therefore, H4 and H5 are not accepted. The study results on the opportunity for growth and security and the opportunity to use and develop human capital are quite different from the work of Adriaenssens et al. [17] and Loemo et al. [5]. These results could be attributed to the differences among Malaysian nursing professionals such that growth and security and the development of human capital did not significantly affect their psychological empowerment. The effect of psychological empowerment on burnout was negative and significant. The results also showed a large effect size $\left(f^{2}=0.503\right)$, so H9 is accepted. The study findings are in accordance with the work of Christina and Leiter [6]. In short, it is believed that psychological empowerment effectively reduces burnout.

The last hypothesis tests the mediating role of psychological empowerment on the relationship between adequate and fair compensation, constitution at work, safe and healthy working conditions, social integration at work, social relevance of work-life, opportunity for growth and security, opportunity to use and develop human capital, work and life span, and burnout. The findings statistically confirm that psychological empowerment mediates the relationship between QWL factors and burnout. However, psychological empowerment did not mediate the effect of the QWL factor, namely safe and healthy working conditions, on the burnout of nursing staff working in Malaysia.

\section{Conclusions}

For the invaluable services rendered by the nursing professionals to the society, it is necessary that they are provided the necessary working conditions to reduce burnout symptoms. As burnout affects many healthcare workers [40], treating the symptoms of the burnout can enhance individuals willing to work for a better healthy society [41,42]. The challenging nature of nursing work makes it one of the difficult professions [1]. The nursing staff in Malaysia are under tremendous pressure due to the demanding nature of the work, and the burnout rate is also high [15]. Right actions from the management staff of the health industry can reduce the burnout effects in enhancing the performance and satisfaction of the health staff. Healthcare institutions are service-focused and have complex working environments. The general operation of healthcare institutions rests on their people, where nursing staff serve as the core of operations. Moreover, due to the nature of nursing work, a healthy work environment is required to reduce the effect of performance negativity to achieve better work performance, especially to stave off the effects of burnout.

The results of this study showed that the burnout among nurses in Malaysia could be managed by providing necessary QWL attributes, namely adequate and fair compensation, constitution at work, safe and healthy working conditions, social integration at work, social relevance of work-life, 
opportunity for growth and security, opportunity to use and develop human capital, and work and life span at the workplace. This study contributes to the existing literature that the all the factors of QWL are not had the same effect on the psychological empowerment, as some have negative effect of the psychological effect as well like opportunity to use and grow human capital and safe and healthy working conditions. This shows that currently Malaysian health industry unable to provide the right kind of human capital development opportunities and safe and healthy working conditions. These workplace resources enable the nursing staff to reduce their turnover intention and reduce their levels of burnout. The attributes of QWL can enhance psychological empowerment and possibly reduce the effects of burnout among nurses in Malaysia [10]. However, all the factors of QWL need to study separately to observe their effect individually, instead of combing them in one latent construct.

The management staff in the nursing industry in Malaysia must consider the QWL factors to help the nurses to reduce their perceptions of burnout. The role of social integration, the perception of fair and adequate compensation, and the social relevance of work-life are important factors that can effectively enhance the nurses' psychological empowerment [43-45]. Moreover, professional training and communication skills for nursing staff would be useful for them to cope with burnout [46]. Relevant policies should improve the perceptions regarding these factors towards better psychological empowerment among nursing staff [47]. Moreover, colleagues are an important source for reducing the effects of psychological stress and reducing the turnover intention among nurses [48].

Nevertheless, rational emotional therapy also positively reduces nursing job stress and burnout [49]. Enhanced psychological empowerment could reduce the effect of burnout among the nursing staff and enable them to provide better service to local and foreign patients [2]. At the personal level, the availability of yoga intervention positively reduces the effects of emotional exhaustion and depersonalization [50]. The increased influx of medical tourists can be tackled well with psychologically empowered nursing staff; thus enabling the country to earn more foreign exchange [2]. As for the limitations, this study adopted a cross-sectional approach due to time and cost constraints. Therefore, the results have limited generalizability. Moreover, data collected from single source in single time increases the probability of the common method variance bias [34]. We performed the exploratory factor analysis and examined that the single factor did not account for the majority of the variance among the measures [33]. Moreover, the items loaded strongly on their respective constructs. Future studies should adopt a long-term design to collect data over a period of time besides involving both nursing staff and management staff. Moreover, the data in this study was collected from the healthcare industry and nursing staff only. Therefore, generalization to other professions or industries is not possible. For this work, the data was collected from nursing staff only, but the healthcare industry works in teams to effectively execute their professional duties. To enhance understanding of the burnout phenomena, future works should further explore the role of fellow nursing staff and the management.

Author Contributions: Conceptualisation, P.Y.P., A.A.M., N.K.S., and R.A.S.; methodology, P.Y.P., A.A.M., N.K.S.; software, A.A.M.; validation, P.Y.P. and N.H.; formal analysis, A.A.M. and N.H.; writing一 original draft preparation, P.Y.P. and N.H.; writing-review and editing, A.A.M., N.K.S., and R.A.S.; supervision, A.A.M., N.K.S., and R.A.S. All authors have read and agreed to the published version of the manuscript.

Funding: The APC funded by Universiti Malaysia Kelantan.

Conflicts of Interest: The authors declare no conflict of interest. All procedures performed in studies involving human participants were in accordance with the ethical standards of the institution and with the 1964 Helsinki declaration and its later amendments or comparable ethical standards. 


\section{Appendix A}

Table A1. Fornell-Larcker Criterion and Heterotrait-Monotrait Ratios.

\begin{tabular}{|c|c|c|c|c|c|c|c|c|c|c|}
\hline & AFC & CWO & OGS & ODH & SHW & SIW & SRW & WLS & PYE & BUT \\
\hline \multicolumn{11}{|c|}{ Fornell-Larcker Criterion } \\
\hline $\mathrm{AFC}$ & 0.939 & & & & & & & & & \\
\hline CWO & 0.674 & 0.947 & & & & & & & & \\
\hline OGS & 0.738 & 0.675 & 0.841 & & & & & & & \\
\hline $\mathrm{ODH}$ & 0.656 & 0.676 & 0.695 & 0.918 & & & & & & \\
\hline SHW & 0.492 & 0.497 & 0.524 & 0.805 & 0.775 & & & & & \\
\hline SIW & 0.632 & 0.637 & 0.706 & 0.657 & 0.410 & 0.862 & & & & \\
\hline SRW & 0.427 & 0.618 & 0.500 & 0.697 & 0.500 & 0.545 & 0.854 & & & \\
\hline SWL & 0.541 & 0.669 & 0.624 & 0.482 & 0.280 & 0.505 & 0.427 & 0.880 & & \\
\hline PYE & 0.687 & 0.689 & 0.712 & 0.583 & 0.369 & 0.724 & 0.563 & 0.611 & 0.844 & \\
\hline BUT & -0.410 & -0.477 & -0.489 & -0.323 & -0.534 & -0.529 & -0.408 & -0.579 & -0.408 & 0.750 \\
\hline \multicolumn{11}{|c|}{ Heterotrait-Monotrait Ratios } \\
\hline $\mathrm{AFC}$ & - & & & & & & & & & \\
\hline CWO & 0.701 & - & & & & & & & & \\
\hline OGS & 0.801 & 0.729 & - & & & & & & & \\
\hline $\mathrm{ODH}$ & 0.669 & 0.679 & 0.749 & - & & & & & & \\
\hline SHW & 0.504 & 0.683 & 0.736 & 0.555 & - & & & & & \\
\hline SIW & 0.689 & 0.516 & 0.803 & 0.698 & 0.467 & - & & & & \\
\hline SRW & 0.449 & 0.685 & 0.565 & 0.745 & 0.573 & 0.593 & - & & & \\
\hline SWL & 0.599 & 0.647 & 0.710 & 0.491 & 0.302 & 0.579 & 0.462 & - & & \\
\hline PYE & 0.690 & 0.735 & 0.736 & 0.885 & 0.361 & 0.765 & 0.591 & 0.623 & - & \\
\hline BUT & 0.393 & 0.499 & 0.505 & 0.489 & 0.385 & 0.557 & 0.565 & 0.421 & 0.586 & - \\
\hline
\end{tabular}

Note: AFC: Adequate and fair compensation; CWO: Constitution in the work organization; OGS: Opportunity to growth and security; ODH: Opportunity to use and develop human capital; SHW: Safe and healthy working condition; SIW: Social integration in work organization; SRW: Social relevance of work-life; WLS: work and life span; PYE: Psychological empowerment; BUT: Burnout.

\section{References}

1. Schaufeli, W.B. The balance of giving and take: Toward a social exchange model of burnout. Int. Rev. Soc. Psychol. 2006, 19, 87-131.

2. Tang, C.F.; Tan, E.C. Tourism-led growth hypothesis in Malaysia: Evidence based upon regime shift co-integration and time-varying Granger causality techniques. Asia Pac. J. Tour. Res. 2015, 20, 1430-1450. [CrossRef]

3. Maslach, C. Engagement research: Some thoughts from a burnout perspective. Eur. J. Work Organ. Psychol. 2011, 20, 47-52. [CrossRef]

4. Meng, L.; Liu, Y.; Liu, H.; Hu, Y.; Yang, J.; Liu, J. Relationships among structural empowerment, psychological empowerment, intent to stay and burnout in the nursing field in mainland China-based on cross-sectional questionnaire research. Int. J. Nurs. Pract. 2015, 21, 303-312. [CrossRef] [PubMed]

5. Loemo, K.; Admasu, B.; Mirkuzie, W. Determinants of Quality of Work Life among Nurses Working in Hawassa Town Public Health Facilities, South Ethiopia: A Cross-Sectional Study. Nurs. Res. Pract. 2017, 2017. [CrossRef]

6. Christina, M.; Leiter, P.M. Understanding the burnout experience: Recent research and its implications for psychiatry. World Psychiatry 2016, 15, 103-111.

7. Khamisa, N.; Peltzer, K.; Oldenburg, B. Burnout in relation to specific contributing factors and health outcomes among nurses: A systematic review. Int. J. Environ. Res. Public Health 2013, 10, 2214-2240. [CrossRef]

8. Aniza, I.; Aidalina, M.; Nirmalini, R.; Inggit, M.C.H.; Ajeng, T.E. Health tourism in Malaysia: The strength and weaknesses. Jurnal Kesihatan Masyarakat 2009, 15, 7-15.

9. Emilia, Z.A.; Noor, H.I. Work-related stress and coping: A Survey on Medical and Surgical nurses in a Malaysian teaching hospital. Jabatan Kesihatan Masyarakat 2007, 13, 55-66. 
10. Permarupan, Y.P.; Al-Mamun, A.; Saufi, R.A. Quality of work life on employee job involvement and affective commitment between the public and private sector in Malaysia. Asian Soc. Sci. 2013, 9, 268-278. [CrossRef]

11. Goh, C.Y.; Marimuthu, M. The Path Towards Healthcare Sustainability: The Role of Organisational Commitment. Procedia Soc. Behav. Sci. 2015, 224, 587-592. [CrossRef]

12. Long, C.S.; Kowang, T.O.; Ping, T.A.; Muthuveloo, R. Investigation on the impact of job stressors on nurses in Malaysia. Asian Soc. Sci. 2014, 10, 67-77. [CrossRef]

13. Aigbogun, O.; Yassin, S.N.; Shoukat, Z. A model for accelerating the growth of health care tourism in Malaysia. J. Bus. Econ. 2013, 4, 169-179.

14. Ahmed, N.; Oranye, N.O. Empowerment, job satisfaction and organisational commitment: A comparative analysis of nurses working in Malaysia and England. J. Nurs. Manag. 2010, 18, 582-591. [CrossRef] [PubMed]

15. Musa, G.; Doshi, D.R.; Wong, K.M.; Thirumoorthy, T. How satisfied are inbound medical tourists in Malaysia? A study on private hospitals in Kuala Lumpur. J. Travel Tour. Mark. 2012, 29, 629-646. [CrossRef]

16. Yagil, D.; Luria, G.; Gal, I. Stressors and resources in customer service roles: Exploring the relationship between core self-evaluations and burnout. Int. J. Serv. Ind. Manag. 2008, 19, 575-595. [CrossRef]

17. Adriaenssens, J.; De Gucht, V.; Maes, S. Determinants and Prevalence of Burnout in Emergency Nurses: A Systematic Review of 25 Years of Research. Int. J. Nurs. Stud. 2015, 52, 649-661. [CrossRef]

18. Maslach, C.; Schaufeli, W.B.; Leiter, M.P. Job burnout. Annu. Rev. Psychol. 2001, 52, 397-422. [CrossRef]

19. WHO_World Health Organisation. Burnout an "Occupational Phenomenon": International Classification of Diseases. Available online: https://www.who.int/mental_health/evidence/burn-out/en/ (accessed on 24 September 2019).

20. Maslach, C.; Jackson, S.E.; Leiter, M.P. MBI: The Maslach Burnout Inventory: Manual; Consulting Psychologists Press: Palo Alto, CA, USA, 2001.

21. Moustou, I.; Panagopoulou, E.; Montgomery, A.J.; Benos, A. Burnout Predicts Health Behaviors in Ambulance Workers. Open Occup. Health Saf. J. 2010, 2, 16-18.

22. Ahola, K.; Hakanen, J. Job strain, burnout, and depressive symptoms: A prospective study among dentists. J. Affect. Disord. 2007, 104, 103-110. [CrossRef]

23. Garrosa, E.; Moreno-Jimenez, B.; Rodriquez-Munoz, B.; Rodriguez-Carvajal, R. Role stress and personal resources in nursing: A cross-sectional study of burnout and engagement. Int. J. Nurs. Stud. 2011, 48, 479-489. [CrossRef] [PubMed]

24. McVickar, A. Workplace stress in nursing: A literature review. J. Adv. Nurs. 2003, 44, 633-642. [CrossRef] [PubMed]

25. Manojlovich, M.; Laschinger, H. The nursing work life model: Extending and refining a new theory. J. Nurs. Manag. 2007, 15, 256-263. [CrossRef] [PubMed]

26. Orgambidez-Ramos, A.; Borrego-Alés, Y. Empowering employees: Structural empowerment as an antecedent of job satisfaction in university settings. Psychol. Thought 2014, 7, 28-36. [CrossRef]

27. Spreitzer, G.M. Taking stock: A review of more than twenty years of research on empowerment at work. In Handbook of Organisational Behaviour; SAGE Publications Ltd.: London, UK, 2008; pp. 54-72.

28. Yiing, L.H.; Ahmad, K.Z.B. The moderating effects of organisational culture on the relationships between leadership behaviour and organisational commitment and between organisational commitment and job satisfaction and performance. Leadersh. Organ. Dev. J. 2009, 30, 53-86. [CrossRef]

29. Spreitzer, G.M. Psychological empowerment in the workplace: Dimensions, measurement, and validation. Acad. Manag. J. 1995, 38, 1142-1465.

30. Walton, R.E. QWL indicators: Prospects and problems. In Measuring the Quality of Working Life: A Symposium on SOCIAL Indicators of Working Life; Portigal, A.H., Ed.; Labour Canada: Ottawa, ON, Canada, 1974; pp. 19-20.

31. Pérez-Fuentes, M.D.C.; Jurado, M.D.M.M.; Martínez, A.M.; Linares, J.J.G. Analysis of the Risk and Protective Roles of Work-Related and Individual Variables in Burnout Syndrome in Nurses. Sustainability 2019, 11, 5745. [CrossRef]

32. Krejcie, R.V.; Morgan, D.W. Determining Sample Size for Research Activities. Educ. Psychol. Meas. 1970, 30, 607-610. [CrossRef]

33. Harman, H.H. Modern Factor Analysis, 3rd ed.; The University of Chicago Press: Chicago, IL, USA, 1976.

34. Podsakoff, P.M.; Mackenzie, S.B.; Podsakoff, N.P. Sources of Method Bias in Social Science Research and Recommendations on How to Control It. Annu. Rev. Psychol. 2012, 63, 539-569. [CrossRef] 
35. Peng, D.X.; Lai, F. Using partial least squares in operations management research: A practical guideline and summary of past research. J. Oper. Manag. 2012, 30, 467-480. [CrossRef]

36. Cain, M.K.; Zhang, Z.; Yuan, K.-H. Univariate and multivariate skewness and kurtosis for measuring nonnormality: Prevalence, influence, and estimation. Behav. Res. Methods 2017, 49, 1716-1735. [CrossRef] [PubMed]

37. Chin, W.W. How to write up and report PLS analyses. In Handbook of Partial Least Squares; Vinzi, V.E., Chin, W.W., Henseler, J., Wang, H., Eds.; Springer: Berlin, Germany, 2010.

38. Hair, J.F.; Ringle, C.M.; Sarstedt, M. Editorial-partial least squares structural equation modeling: Rigorous applications, better results, and higher acceptance. Long Range Plan. 2014, 46, 1-12. [CrossRef]

39. Cohen, J. Statistical Power Analysis for the Behavioral Sciences, 2nd ed.; Lawrence Earlbaum Associates: Hillsdale, NJ, USA, 1988.

40. Pérez-Fuentes, M.D.C.; Jurado, M.D.M.M.; Martínez, A.M.; Linares, J.J.G. Burnout and Engagement: Personality Profiles in Nursing Professionals. J. Clin. Med. 2019, 8, 286. [CrossRef] [PubMed]

41. Martos, A.; Pérez-Fuentes, M.D.C.; Molero, M.D.M.; Gázquez, J.J.; Barragán, M.M.S.A.B. Burnout y engagement en estudiantes de Ciencias de la Salud. Eur. J. Investig. 2018, 8, 23-36. [CrossRef]

42. Bagley, C.; Abubaker, M.; Sawyerr, A. Personality, Work-Life Balance, Hardiness, and Vocation: A Typology of Nurses and Nursing Values in a Special Sample of English Hospital Nurses. Adm. Sci. 2018, 8, 79. [CrossRef]

43. John, W.N.; Cavanagh, A.M. Development of an international tool to measure nurse job satisfaction by testing the Healthcare Environment Survey beyond Jamaica and the United States to Scotland: A cross sectional study utilizing exploratory factor analysis. Int. J. Healthc. Manag. 2018, 11, 314-318.

44. Siegal, M.; McDonald, T. Person-organisation value congruence, burnout, and diversion of resources. Pers. Rev. 2004, 33, 291-301. [CrossRef]

45. Okpala, P. Nurses' perspectives on the impact of management approaches on the blame culture in health-care organisations. Int. J. Healthc. Manag. 2018, 11, 1-7. [CrossRef]

46. Ercolani, G.; Varani, S.; Peghetti, B.; Franchini, L.; Malerba, M.B.; Messana, R.; Sichi, V.; Pannuti, R.; Pannuti, F. Burnout in Home Palliative Care: What Is the Role of Coping Strategies? J. Palliat. Care 2019, 35, 46-52. [CrossRef]

47. Kartal, N. Evaluating the relationship between work engagement, work alienation and work performance of healthcare professionals. Int. J. Healthc. Manag. 2018, 11. [CrossRef]

48. Heijden, B.V.; Mahoney, C.B.; Xu, Y. Impact of job demands and resources on Nurses' burnout and occupational turnover intention towards an age-moderated mediation model for the Nursing profession. Int. J. Environ. Res. Public Health 2019, 16, 2011. [CrossRef] [PubMed]

49. Kim, H.L.; Yoon, S.H. Effects of Group Rational Emotive Behavior Therapy on the Nurses' Job Stress, Burnout, Job Satisfaction, Organisational Commitment and Turnover Intention. J. Korean Acad. Nurs. 2018, 48, 432-442. [CrossRef] [PubMed]

50. Alexander, G.K.; Rollins, K.; Walker, D.; Wong, L.; Pennings, J. Yoga for Self-Care and Burnout Prevention Among Nurses. Workplace Health Saf. 2015, 63, 462-470. [CrossRef] [PubMed]

(C) 2020 by the authors. Licensee MDPI, Basel, Switzerland. This article is an open access article distributed under the terms and conditions of the Creative Commons Attribution (CC BY) license (http://creativecommons.org/licenses/by/4.0/). 